\title{
Epidemiological aspects of cryptosporidiosis in Beni-Suef Governorate
}

\author{
M. A. Ibrahim ${ }^{1}$, S. M. Abo El-Hadid ${ }^{2}$, M. H. Meabed ${ }^{3}$ \\ ${ }^{1}$ Department of Hygiene, Management and Zoonoses, Faculty of Veterinary Medicine Beni-Suef University, Beni-Suef, Egypt \\ ${ }^{2}$ Department of Parasitology, Faculty of Veterinary Medicine Beni-Suef University, Beni-Suef, Egypt \\ ${ }^{3}$ Department of Pediatrics, Faculty of Medicine, Beni-Suef University, Beni-Suef, Egypt
}

\begin{abstract}
The aim of this study was to evaluate the status of infection by Cryptosporidium spp. in Beni-Suef Governorate. For this purpose, 305 fecal samples from animals (75 calves, 74 dairy cattle, 86 lambs and 70 sheep) and 177 human stool samples were collected from inhabitants and out patients of the university hospital in Beni-Suef who suffering from gastroenteritis mainly diarrhea. The samples were examined using Modified Ziehl-Neelsen technique. An over all of animal cryptosporidiosis was $6.8 \%$. Cryptosporidium oocysts could be detected in calves, dairy cattle, lambs and adult sheep at a rate of $12 \%, 2.75 \%, 6.97 \%$ and $0 \%$ respectively. Concerning humans Cryptosporidium oocysts could be detected at a rate of $14.56 \%$ and $2.7 \%$ in diarrheic individuals and apparently healthy ones. Infection rate in females $(\mathbf{1 4 . 2 8 \% )}$ was higher than in males $(6 \%)$ and the children (1-10 years old) were highly susceptible to cryptosporidiosis than adults. Eighty-nine selected diarrheic feacal samples (79 from humans and 10 from calves) were selected and examined by cryptosporidium antigen capture ELISA beside their examination by Modified Ziehl-Neelsen technique. No significant differences were found between the two techniques in terms of epidemiological study.
\end{abstract}

Cryptosporidiosis is a protozoan infection caused by Cryptosporidium species. The protozoon colonizes epithelial cells of the gastrointestinal tract of vertebrates causing enteric diseases in man and animals (Janoff and Reller 1987).

The genus Cryptosporidium contains several species that were identified in a vast sort of hosts including mammals, birds, fishes and reptiles (Janoff and Reller 1987). Although there are nineteen species described (Levine, 1984) so far, only Cryptosporidium muris and Cryptosporidium parvum are associated with mammals (Fayer and Ungar 1986). Cryptosporidium parvum is generally regarded as the major species responsible for clinical disease in humans and domestic animals (Tzipori and Ward 2002). Nevertheless, difficulties in the species identification through the use of immunologic tests and molecular biology for positive confirmation, so far, existing species, the term Cryptosporidium spp. has the preference when regarded to those secluded from humans (Meinhardt et al., 1996).

Interest in Cryptosporidium by veterinary medical profession was stimulated in 1971 when this protozoan was first reported to be associated with bovine diarrhea (Pohlenz et al., 1978).
Since this time, numerous case reports from different animals were now present in the literature and one species, C. parvum, is recognized as an important cause of the neonatal diarrhea in calves and lambs (Angus, 1983). In 1980,Cryptosporidium isolates obtained from calves, lambs and humans with severe diarrhea readily infected seven other species of animals (Tzipori et al., 1980a). The transmission of human isolates, which induced acute diarrhea in lambs indistinguishable from that caused by other animal isolates, strongly indicated the potential zoonotic nature of Cryptosporidium (Tzipori et al., 1980b).

The first case of human cryptosporidiosis was reported in 1976 (Nime et al., 1976) Subsequent reports were rare until it was recognized that Cryptosporidium (C. parvum) may produce a short-term diarrheal illness in immunocompetent persons and a prolonged, lifethreatening cholera-like illness in immunodeficient patients, especially those with AIDS (Current et al., 1983 and Crawford and Vermund, 1988).

Unlike other intestinal pathogens, Cryptosporidium can infect several different hosts, including humans, cattle, sheep, goats, pigs and horses. It can survive in most environments for 
long periods of time due to its "hardy cyst" (Keusch et al., 1995) that inhabits all climates and localities.

Exposure to $C$. parvum oocysts, either directly through contact with infected humans or animals, or indirectly by drinking or eating food washed with contaminated water may lead to acute diarrhea. C. parvum causes an acute, selflimiting infection and diarrheal disease in immunocompetent people, in whom the onset may be rapid (3-7days), depending on a combination of host factors (age, presence of maternal antibodies or previous exposure, and infection dose) and parasite related factors (origin and age of oocysts and species/genotype) (Tzipori and Ward, 2002). In children and immunocompromised individuals, cryptosporidiosis can be a serious, unrelenting and lifethreatening problem (Blanshard et al., 1992). Although the prevalence of cryptosporidiosis in people with AIDS is not high $(5-15 \%$ in developed countries), the lack of effective treatment makes it one of the most troublesome among the opportunistic infections associated with AIDS.

Cryptosporidiosis was initially diagnosed in intestinal biopsy (Meisel et al., 1976 and Nime et al., 1976) Pohlenz, et al. (1978) described the finding of Cryptosporidium oocysts in fecal material of young calves, since then the diagnosis of this protozoan has became essentially coprologic, although it shows some limitations. Detection depends on the presence of intact oocysts in feces. The earliest method of staining of a fecal smear with modified acid fast remains the quickest and the easiest to perform if the sample is reasonably fresh although acid fast stains may fail to detect Cryptosporidium when being less than 100.000 oocysts/gm in formed stool or 10.000 oocyst/gm in a watery stool (Weber, et al., 1991). Other methods used in clinical diagnostic laboratories include direct and indirect immunofluorescence microscopy and ELISA. These are highly sensitive techniques and are useful for screening large numbers of specimens in a short time period. That does not rely on microscopic skills.

The present study was performed to investigate the status of cryptosporidiosis infection in Beni-Suef Governorate and compare ELISA with Modified Ziehl-Neelsen technique for detection in Cryptosporidium oocysts in feces.

\section{Material and methods}

Samples from livestock. 305 fecal samples (75 from calves, 74 from dairy cattle, 86 from lambs and 70 from adult sheep) were collected from Beni-Suef Governorate from the sites where the stool samples of humans were collected. Cryptosporidium oocysts were examined by modified Ziehl-Neelsen technique (Henriksen and Pohlenz, 1981).

Samples from humans. 177 stool samples were collected from the inhabitants residing Beni-Suef city and from out patients of the university hospital in Beni-Suef who suffering from gastroenteritis mainly diarrhea. Data concerning age and sex were recoded. Stool smears from each sample was prepared, stained by modified Ziehl-Neelsen procedure according to (Henriksen and Pohlenz, 1981) and then examined microscopically for oocysts of Cryptosporidium.

Cryptosporidium antigen capture ELISA (AC ELISA). Coproantigen of Cryptosporidium parvum was detected in fecal samples using Cryptosporidium AC-ELISA kit (R-Biopharm AG: Darmstad, Germany, Art. No: C12010115). Eighty-nine selected stool samples (79 from diarrheic humans and 10 from diarrheic calves) were subjected to examination. Briefly, fecal samples were diluted with buffered $\mathrm{NaCl}$ solution 1:10 (v/v). $100 \mu 1$ of samples, positive and negative controls were pipetted into the wells. $100 \mu 1$ of HRP conjugated mouse monoclonal antibody was added to each well, mixed well and incubated for $60 \mathrm{~min}$ at room temperature. Wells were decanted and washed for five times with washing buffer. Then $100 \mu 1$ of tetramethyl-benzidine substrate working solution was added to each well and incubated for $15 \mathrm{~min}$. in dark place. Reaction was stopped by adding $50 \mu 11 \mathrm{M}$. $\mathrm{H}_{2} \mathrm{SO}_{4}$. Absorbance was measured at $450 \mathrm{~nm}$. ELISA results obtained were compared with those obtained by modified Ziehl-Neelsen technique.

The protozoan parasite Cryptosporidium causes acute gastroenteritis in both humans and animals. It has become an important pathogen all-over the world. Cryptosporidium spp. may cause asymptomatic or symptomatic acute infections of the digestive system in immunocompetant hosts, but life-threatening disease in immunocompromised ones.

Table (1) indicated the prevalence of Cryptosporidium spp. among the examined livestocks. Cryptosporidium oocysts were identified in calves, dairy cattle, lambs and sheep 


\section{Results and Discussion}

Table (1): Prevalence of Cryptosporidium species among the examined animals by Modified ZiehlNeelsen technique.

\begin{tabular}{lccc}
\hline \multirow{2}{*}{ Species of animal } & No. of samples & \multicolumn{2}{c}{ Infected animals } \\
\cline { 3 - 4 } & & Number & \% \\
\hline Calves & 75 & 9 & 12 \\
Dairy cattle & 74 & 2 & 2.7 \\
Lambs & 86 & 6 & 6.97 \\
Adult sheep & 70 & 0 & 0 \\
Total & 305 & 17 & 5.57 \\
\hline
\end{tabular}

Table (2): Prevalence of Cryptosporidium species in apparently healthy and diarrheic human population using Modified Ziehl-Neelsen technique.

\begin{tabular}{lccc}
\hline \multirow{2}{*}{ Type of samples } & No. of samples & Number & Positive cases \\
\cline { 3 - 4 } & & 15 & 14.56 \\
\hline Individuals with GIT disturbances & 103 & 2 & 2.7 \\
Apparently healthy individuals & 74 & 17 & 9.60 \\
Total & 177 & & \\
\hline
\end{tabular}

Table (3): Prevalence of Cryptosporidium spp. in human population according age and sex using Modified Ziehl-Nelseen technique.

\begin{tabular}{|c|c|c|c|c|c|c|}
\hline \multirow[b]{2}{*}{ Age } & \multicolumn{2}{|c|}{ Female } & \multicolumn{2}{|c|}{ Males } & \multicolumn{2}{|c|}{ Total } \\
\hline & Number & +ve cases & Number & +ve cases & Number & +ve cases \\
\hline $1-10$ years & 43 & $\begin{array}{c}8 \\
(18.6 \%)\end{array}$ & 52 & $\begin{array}{c}5 \\
(9.61 \%)\end{array}$ & 95 & $\begin{array}{c}13 \\
(13.68 \%)\end{array}$ \\
\hline $11-60$ years & 34 & $\begin{array}{c}3 \\
(8.82 \%)\end{array}$ & 48 & $\begin{array}{c}1 \\
(2.08 \%)\end{array}$ & 82 & $\begin{array}{c}4 \\
(4.87 \%)\end{array}$ \\
\hline Total & 77 & $\begin{array}{c}11 \\
(14.28 \%)\end{array}$ & 100 & $\begin{array}{c}6 \\
(6 \%)\end{array}$ & 177 & $\begin{array}{c}17 \\
(9.60 \%)\end{array}$ \\
\hline
\end{tabular}

Table (4): Comparison of Modified Ziehl-Neelsen technique and AC ELISA test for detection of Cryptosporidium oocyst in feces of human and calves.

\begin{tabular}{cccc}
\hline Type of samples & No. of samples & MZN technique & ELISA test \\
\hline Diarrheic humans & 79 & 9 & 10 \\
Diarrheic calves & 10 & $(11.39 \%)$ & $(12.65 \%)$ \\
Total & & 1 & 1 \\
& 89 & $(10 \%)$ & $(10 \%)$ \\
& & $(11.23 \%)$ & 11 \\
\end{tabular}


at a rate of $12 \%, 2.7 \%, 6.97 \%$ and $0 \%$ respectively. All positive calves and lambs were suffered from diarrhea (some of them had watery diarrhea). Calves usually become infected with Cryptosporidium between one and four weeks of age, and the duration of infection is short, lasting around two weeks, (Fayer et al., 1998b and Handley et al., 1999). Cryptosporidium spp. were identified in the feces of livestock (either normal or diarrheic) in Egypt and all-over the world by many authors as, Wahba (1994) 5.3\% in lambs and $2.5 \%$ in goats at Qalubia Governorate, Abdel-Wahed (1999) 68.30\% in lambs aged less than one month, Khalil (2000) $16.5 \%$ in sheep and $29.1 \%$ in goats, Rhee, et al. (1991) "22\% in calves", Wee, et al. (1996) "14.4\% in calves", Learmonth, et al. (2003) " $0.27 \%$ in cattle and $4.55 \%$ in calves", Mahdi and Ali (2002) "20\% in cattle, $13.3 \%$ in sheep and $12 \%$ in goats" ,Chalmers et al. (2002) "43\% in healthy sheep" and Monica et al., (2004) " $35.5 \%$ out of 971 calves". The infection by Cryptosporidium spp. is probably present in every domestic cattle herd in the world with asymptomatic infections. Prolonged oocyst excretion by adult cattle recognized as a major and continuous source of environmental contamination. Accordingly, they constitute potential sources for newborn calves contract the infection at a very young age (Tzipori and Ward, 2002). The negative result in sheep in this study may be due to the low number of examined sheep or the possible limited level of Cryptosporidium infection in the examined area. This finding indicated that calves constituted a major risk as a source of cryptosporidiosis in the environment, consequently persons handling or in contact to calves are at greater risk of zoonotic infection from Cryptosporidium (Monica, et al., 2004).

The overall positive rate of cryptosporidiosis among the 177 individuals examined was $9.60 \%$ of which $14.56 \%$ out of 103 were suffered from diarrhea and $2.7 \%$ out of 74 were apparently healthy (Table 2). Cryptosporidium is a highly infectious protozoan that causes diarrheal illness around the world. The human host range is broad and includes immunocomprmised people with AIDS, children in developing countries and immunocompetent individuals. Within many of these groups, the manifestations of disease are diverse, ranging from asymptomatic infections to life-threatening illness (Douglas, 1999). In a review of over 130,000 presumably immunocompetent patients with diarrhea, $6.1 \%$ in developing areas and $2.1 \%$ in developed areas with diarrhea had Cryptosporidium infections (Adal et al., 1995). Among the HIV-positive patients with diarrhea, the percentages of Cryptosporidium infections rose to $24 \%$ and 14\% (Adal et al., 1995). Also Cho, et al. (1993) reported $22 \%$ fecal oocyst positive rate out of 230 outpatients of private hospital. The low level of Cryptosporidium infection (2.6\%) reported in apparently healthy individuals indicated that infection are rare in persons without symptoms, suggesting that Cryptosporidium should not be regarded as an opportunistic parasite (Navin, 1985). On the other hand, excretion of oocysts of Cryptosporidium by persons not complaining from any specific clinical symptoms such as diarrhea indicated that some individuals may remain asymptomatic during infection and therefore there was a carrier status of cryptosporidiosis (Checkley et al., 1997). There is circumstantial evidence of human cryptosporidiosis associated with exposure to infected livestock, particularly young cattle, animal manure and contaminated water (Fayer et al., 2000 and Thompson, 2003). Although farm workers and visitors to farms might have contracted cryptosporidiosis by direct contact, indirect zoonotic transmission of Cryptosporidium of cattle origin via water has long been considered to be the most important zoonotic source of human infection (Casmir, et al., 1997).

The positive rate of cryptosporidiosis in the examined females $(16.66 \%)$ was higher than that of males $(7.5 \%)$ (Table, 3). Children in the age group 1-10 years showed higher infection rate $(13.68 \%)$ than that in the age group ranged from $11-60$ years $(6.66 \%)$. This result was similar to that reported by Jae et al. (2004) who detected cryptosporidiosis in females and males at a rate of $4.8 \%$ and $2.6 \%$ respectively. In developing countries, cryptosporidiosis is a common cause of persistent diarrhea among children (Leav, 2003). Cryptosporidium oocysts could be detected in children by Laubach, et al. (2004) at a rate ranged from $16-44 \%$. They found that female children in 2 to 5 year age group were having a higher prevalence of infection than males. Out of 532 children with persistent diarrhea, $166(31.2 \%)$ were found to harbor $C$. parvum (Tumwine et al., 2003). Casemore (1990), the peak incidence of cryptosporidiosis was in children aged 1-5 years. But Chai, et al. (2001) the peak positive rates in older age groups. On the other hand Xiao, et al. (2001) 
found no significant difference in infection due to age. Children had a tendency to be less aware of hygiene practices and played in dirty yards contaminated with fecal material, so the probability to be get infected is high.

For comparison of Modified Ziehl-Neelsen technique and ELISA test for detection of Cryptosporidium oocyst in stool, 79 samples from diarrheic persons and 10 samples from diarrheic calves were subjected to analysis. The results obtained (Table 4) indicated that there was no significant difference between the 2 tests, although ELISA test was found to give higher positive rates $(12.55 \%)$ than Modified ZiehlNeelsen technique (11.39\%). Previously, the "gold standard" for detecting Cryptosporidium oocysts in stool was a modified acid-fast stain of a fecal smear. However, the sensitivity for detection of Cryptosporidium is substantially better with enzyme-linked immunosorbent assay (Katanik et al., 2001).

The stool immunoassays provide adequate sensitivities, cost-effective and rapid results, particularly in a potential waterborne outbreak situation and in patients with low parasitic numbers (DuPont et al., 1995 and Fayer et al., 1998a). In patients who are infected with Cryptosporidium, the use of routine diagnostic method such as modified acid-fast staining may be insufficient to demonstrate the presence of this organism (Current and Garcia, 1991 and Kehl et al., 1995). As acute infections with Cryptosporidium resolve, the number of oocysts dramatically decreases. Also, the number of Cryptosporidium oocysts passed by patients, including those with human immunodeficiency virus disease, varies from day to day and week to week. None of these techniques allows discrimination regarding the species of origin of the oocysts. Only genetic techniques, including PCR, can help determine the possible source and risk to human health. During this study we found that most samples of humans and animals had a mixed infection of Cryptosporidium spp. As the sizes of the oocysts in feces were not even. Future study will be necessary to verify the mixed infection status in both animals and humans.

\section{References}

Abdel-Wahed, M. M. (1999): Cryptosporidium infection among sheep in Qalubia Governorate, Egypt. J. Egypt. Soc. Parasitol., 29 (1): 113-118.

Adal, K. A.; Sterling, C. R. and Guerrant, R. L. (1995): Cryptosporidium and related species. In Infections of the gastrointestinal tract, Blaser, M. J.; Smith, P. D.; Ravvdin,
J. I.; Greenberg, H. B. and Gurrant R. L., Ravin Press, New York (ed.), 1107-1128.

Angus, K. W. (1983): Cryptosporidiosis in man, domestic animals and birds: a review. J.R. Soc. Med., 76: 62-70.

Blanshard, C.; Jackson, A. M.; Shanson, D. C.; Francis, N. and Gazzard, B. G. (1992): Cryptosporidiosis in HIV seropositive patients. Q. J. Med., 85: 813-823.

Casemore, D. P. (1990): Epidemiological aspects of human cryptosporidiosis. Epid. Infect., 104: 1-28

Casmir, E. T.; Fayer, R. and Ronald, S. (1997): Cryptosporidiosis-human and animal epidemiology. In Cryptosporidium and cryptosporidiosis Boca Raton Fla (Fayer, R., ed.), CRC Press, 65-92.

Chai, J. Y.; Kim, N. Y. and Guk, S. M. (2001): High prevalence and seasonality of cryptosporidiosis in small rural village occupied predominantly by aged people in the republic of Korea. Am. J. Trop. Med. Hyg., 56: 518-522.

Chalmers, R. M.; Elwin, K.; Reilly, W. J.; Irvine, H.; Thomas, A. L. and Hunter, P. R. (2002): Cryptosporidium in farmed animals: the detection of a novel isolate in sheep. Int. J. Parasitol., 32 (1): 21-6.

Checkley, W.; Gilman, R. H. and Epstein, L. D. (1997): Asymptomatic and symptomatic cryptosporidiosis: their acute effect on weight gain in Peruvian children. Am. J. Epid., 145: 156-163.

Cho, M. H.; Kim, A. K. and Im, K. (1993): Detection of Cryptosporidium oocysts from outpatients of the Severance hospital. Korean J. Parasitol., 31: 193-199.

Crawford, F. G; and Vermund, S. H. (1988): Human cryptosporidiosis. Crit. Rev. Microbiol., 16: 113-159.

Current, W. L.; Reese, N. C.; Ernest, J. V.; Bailey, W. S.; Heyman, M. B. and Weinstein, M. D. (1983): Human cryptosporidiosis in immunocompetent and immunodificient persons: studies of an outbreak and experimental transmission. N. Engl. J. Med., 308: 12521257.

Current, W. L. and Garcia, L. S. (1991): Cryptosporidiosis. Clin. Microbiol. Rev., 3: 325-358.

DuPont, H. L.; Chappell, C. L.; Sterling, C. R.; Okhuysen, P. C.; Rose, J. B. and Jakubowski, W. (1995): The infectivity of Cryptosporidium parvum in healthy volunteers. N. Engl. J. Med., 332: 855-859.

Douglas, P. C. (1999): New lights into human cryptosporidiosis. Microbiol. Reviews. 12 (4): 554-563. Fayer, R.; Trout, J. M. and Jenkins, M. C. (1998a): Infectivity of Cryptosporidium parvum oocysts stored in water at environmental temperatures. J. Parasitol., 84: 1165-1169.

Fayer, R. and Ungar, B. L. P. (1986): Cryptosporidium spp and Cryptosporidiosis. Microbiol. Rev., 50: 458-483.

Fayer, R.; Gasbaree, L.; Paquali, P.; Canals, A.; Almeria, S. and Zrlenga, D. (1998b): Cryptosporidium parvum in bovine neonates: dynamic, clinical, parasitic and immunologic patterns. Int. J. Parasitol., 28 (1): 49-56.

Fayer, R.; Morgan, U. and Steve, J. (2000): Epidemiology of Cryptosporidium: transmission, detection and identification. Int. J. Parasitol., 30: 1305-1322.

Handley, R. M.; Cockwill, C.; McAllister, T. A.; Jelinski, M.; Morck, D. W.; Olson, M. E. (1999): Duration of naturally giardiosis and cryptosporidiosis in dairy calves and their association with diarrhea. J. Am. Vet. Med. Assoc., 214: 391-396.

Henriksen, S. A. and Pohlenz, J. F. L. (1981): Staining of Cryptosporidium by a modified Ziehl-Neelsen technique. Act. Vet. Scand., 22: 594-596.

Jae, R. Y. U.; Jong-Kyu, L.; Min, S.; Seok, I. I. K.; 
Woon-Mok, S.; Sun, H.; Hae-Yeon, C. and Tong-Soo, K. (2004): Prevalence of Cryptosporidiosis among the villagers and domestic animals in several rural areas of Korea. The Korean J. Parasitol., 42 (1): 1-6.

Janoff, E. N. and Reller, L. B. (1987): Cryptosporidium species, a protean protozoan. J. Clin. Microbiol., 25: $967-$ 975.

Katenik, M. T.; Schneider, S. K. and Rosenblatt, J. I. (2001): Giardia/Cryptosporidium rapid assay and ProSpecT Giardia/Cryptosporidium micrplate assay for detection of Giardia and Cryptosporidium in fecal specimens. J. Clin. Microbiol , 39: 4523-4525.

Kehl, K. C.; Cicirello, H. and Havens, P. L. (1995): Comparison of four different methods for the detection of Cryptosporidium species. J. Clin. Microbiol., 33: 416-418.

Keusch, G. T.; Hamer, D.; Joe, A.; Kelley, M.; Griffiths, J.; and Ward, H. (1995): "Cryptosporidia - who is at risk?" Schweiz. Med. Wochenschr., 125 (18): 899-908.

Khalil, F. A. (2000): Studies on cryptosporidium in sheep and goats. Ph. D. Thesis, Fac. Vet. Med. Cairo Univ.

Laubach, H. E.; Bentley, C. Z.; Ginter, E. L.; Spalter, J. S. and Jensen, L. A. (2004): A study of risk factors associated with the prevalence of Cryptosporidium in villages around Lake Atitlan, Guatemala. Braz. J. Infect. Dis., 8: 4.

Learmonth, J. J.; Ionas, G.; Pita, A. B. and Cowie R. S. (2003): Identification and genetic characterization of Giardia and Cryptosporidium strains in humans and dairy cattle in the Waikato Region of New Zealand. Water Sci. Technol., 47 (3): 21-6.

Leav, B. A; Mackay, M. and Ward, H. D. (2003): Cryptosporidium species: new insights and old challenges. Clin. Infect. Dis., 36: 903-908.

Levine, D. N. (1984): Taxonomy and review of the coccidian genus Cryptosporidium (Protozoa, Apicomplexa). J. Protozool., 31: 94-98.

Mahdi, N. K. and Ali, N. H. (2002): Cryptosporidiosis among animal handlers and their livestock in Basrah, Iraq. East. Afr. Med. J., 79 (10): 550-3.

Meisel, J. L.; Perera, D. R.; Meligro, C. and Rubin, C. E. (1976): Overwhelming watery diarrhea associated with a Cryptosporidium in an immunosuppressed patient. Gastroenterol., 70: 1156-1160.

Meinhardt, P. L.; Casemore, D. P. and Miller, K. B. (1996): Epidemiologic aspects of human cryptosporidiosis and the role of waterborne transmission. Epidem. Rev., 18: 118-136,

Monica, S.; James, M. T.; Lihua, X.; ling, Z.; Ellis, G. and Ronald, F. (2004): Prevalence and age-related variation of Cryptosporidium species and genotype in dairy calves. Vet. Parasitol., 122 (2-21): 103-117.

Navin, T. R. (1985): Cryptosporidiosis in humans: Review of recent epidemiologic studies. Europ. J. Epid. (Historical Archive) Issue, 1 (2): 77-83.

Nime, F. A.; Burek, J. D.; Page, D. L.; Holscher, M. A. and Yardley, J. H. (1976): Acute enterocolitis in a human being infected with the protozoan Cryptosporidium. Gastroenterol., 70: 592-8.

Pohlenz, J.; Moon, H.W.; Cheville, N.F. and Bemrick, W.J. (1978): Cryptosporidiosis as a probable factor in neonatal diarrhea of calves. J. Am. Vet. Med. Assoc. 172.

Rhee, J. K.; Seu, Y. S. and Park, B. K. (1991): Isolation and identification of Cryptosporidium from various animals in Korea. I. Prevalence of Cryptosporidium in various animals. Korean J. Parasitol., 29: 139-148.

Thompson, R. C. A. (2003): Molecular epidemiology of Giardia and Cryptosporidium infections. J. Parasitol., 89: 134-140.

Tumwine, J. K.; Kekitiinwa, A.; Nabukeera, N.; Akiyoshi, D. E.; Rich, S. M.; Widmer, G.; Feng, X. and Tzipori, S. (2003): Cryptosporidium parvum in children with diarrhea in Mulago Hospital, Kampala, Uganda. Am. J. Trop. Med. Hyg., 68 (6): 710-5

Tzipori, S. and H. Ward (2002): Cryptosporidiosis: biology, pathogenesis and disease. Microbs. and Infect., 4: 1047-1058

Tzipori, S.; Angus, K. W. and Gray, E. W. (1980a): Campbell, E.W. Gray, Cryptosporidium: evidence for a single species genus, Infect. Immun. 30: 884-886.

Tzipori, S.; Angus, K. W. and Gray, E. W. (1980b): Campbell, Vomiting and diarrhea associated with cryptosporidial infection, N. Engl. J. Med., 303: 818.

Wahba, A. M. A. S. (1994): Microbiological studies on Cryptosporidia and Sarcocystis in animals and their impact on their health. Ph. D. Thesis Parasitol. Fac. Vet. Med. Zagazig Univ.

Weber, R.; Bryan, R.; Bishop, S.; Wahiquist, J.; Sullivan, D. and Juranek, D. (1991): Threshold of detection of Cryptosporidium oocysts in human stools: evidence of low sensitivity of current diagnostic methods. J. Clin. Microbiol., 29:1323-1327.

Wee, S.; Joo, H. D. and Kang, Y. B. (1996): Evaluation for detection of Cryptosporidium oocysts in diarrheal feces of calves. Korean J. Parasitol., 34: 121-126.

Xiao, L.; Bern, C. and Limor, J. (2001): Identification of 5 types of cryptosporidium parasites in children in Lima, Peru. J. Infect. Dis., 183: 492-7. 